\title{
sciendo
}

\section{Enkephalinase activity is modified and correlates with fatty acids in frontal cortex depending on fish, olive or coconut oil used in the diet}

\author{
Ana B. Segarra ${ }^{1}$, Isabel Prieto ${ }^{1}$, Magdalena Martinez-Canamero ${ }^{1}$, \\ Jose-Ignacio Ruiz-SAnZ ${ }^{2}$, M. Begona RUiz-Larrea ${ }^{2}$, Marc De Gasparo ${ }^{3}$, \\ Inmaculada BANEGAS ${ }^{1}$, Stefan Zor AD ${ }^{4}$, Manuel RamireZ-SANCHEZ ${ }^{1}$
}

\begin{abstract}
${ }^{1}$ Department of Health Sciences, University of Jaen, Jaen, Spain; ${ }^{2}$ Department of Physiology, Medicine and Nursing School, University of the Basque Country UPV/EHU, Leioa, Spain; ${ }^{3}$ Cardiovascular \& Metabolic Syndrome Adviser, Rossemaison, Switzerland; ${ }^{4}$ Institute of Experimental Endocrinology, Biomedical Research Center, Slovak Academy of Sciences, Bratislava, Slovakia

E-mail:msanchez@ujaen.es
\end{abstract}

\begin{abstract}
Objective. Enkephalins are neuropeptides involved in functions such as pain modulation and/ or cognitive processes. It has been reported that dietary fat modifies enkephalins in the brain. Since enkephalins are hydrolyzed by enkephalinases, the study of the influence of dietary fats, differing in their degree of saturation, on brain fatty acids content and enkephalinase activity is important to understand its regulatory role on neuropeptides under different type of diets.

Methods. We analyzed enkephalinase activity, assayed with alanine- $\beta$-naphthylamide as substrate, in frontal cortex of adult male rats fed diets supplemented with fish oil, olive oil or coconut oil, which markedly differed in the saturation of their fatty acids.

Results. Rats fed a diet enriched with coconut oil had lower soluble enkephalinase activity than the group fed olive oil $(\mathrm{p}<0.01)$ and fish oil $(\mathrm{p}<0.05)$ whereas rats fed a diet enriched with fish oil had lower membrane-bound enkephalinase activity than the group fed with olive $(\mathrm{p}<0.001)$ or coconut oil $(\mathrm{p}<0.05)$. Significant negative correlations were observed between certain fatty acids and enkephalinase activities in the groups fed with olive and coconut oils. No correlations were observed in the group fed with fish oil.

Conclusions. Dietary fat modifies enkephalinase activity in the frontal cortex depending on the degree of saturation of the used oil. It is postulated that the functions, in which enkephalins are involved, such as pain modulation or cognitive functions, may also be affected according to the type of oil used in the diet.
\end{abstract}

Key words: diet, fatty acids, enkephalinases, enkephalins, frontal cortex

Endogenous opioids and their receptors are broadly distributed throughout the nervous system. They have been implicated in various functions such as analgesia, cognitive processes, cardiovascular functions or feeding behavior (Bodnard 2018; Corder et al. 2018). It has been reported that enkephalins, released in the central nervous system, act as anxiolytic agents, particularly in the cortico-limbic system (Narita et al. 2006; Hernandez et al. 2015). Enkephalin functions are in particular regulated by aminopeptidases, called enkephalinases, such as membrane-bound alanyl aminopeptidase (EC 3.4.11.2) (Danziger 2007), puromycin-sensitive aminopeptidase (EC 3.4.11.14) (Thompson and Hersh 2004), leucyl-aminopeptidase (EC 3.4.11.1) (Gibson et al. 1991) or placentalleucyl-aminopeptidase (EC 3.4.11.3) (Matsumoto et

Corresponding author: Dr. M. Ramirez-Sanchez, Unit of Physiology, Department of Health Sciences, University of Jaen, 23071 Jaen, Spain; phone: 34-953-212302; fax: +34 953 212943; e-mail: msanchez@ujaen.es. 
al. 2001). Therefore, these enzymes may be involved in the modulation of brain functions by enkephalins (Banegas et al. 2017).

Dietary fat modifies enkephalin expression in brain of rats (Chang et al. 2007; Chang et al. 2010). Enkephalins of the frontal cortex are involved especially in functions such as pain modulation (Hardy and Haigler 1985) or cognitive processes (Henry et al. 2017). The aim of our study was to analyze the effect of the diverse degree of fatty acid saturation of three different diets on the fatty acid composition and enkephalinase activity in the frontal cortex of adult male rats. We measured enkephalinase activity (EC 3.4.11.2, aminopeptidase $M$ ), particularly the one assayed with alanine- $\beta$-naphthylamide as substrate (Hersh et al. 1987), which has been considered as the major enkephalin degrading enzyme in the brain (Hersh 1985). The diets were supplemented with fatty acids clearly differing in their degrees of saturation: fish oil (F, rich in polyunsaturated fatty acids, PUFAs), olive oil ( $\mathrm{O}$, rich in monounsaturated fatty acids, MUFAs), and coconut oil (C, rich in saturated fatty acids, SAFAs). Since the dietary fat modifies enkephalinase activity in the frontal cortex, the functions in which its endogenous substrates are involved may also be changed.

\section{Materials and methods}

Experimental design. Three groups ( $\mathrm{n}=8$ each) of normal adult male Wistar rats (six-week-old, weighing 200-250 g, kept at room temperature of $22 \pm 2^{\circ} \mathrm{C}$, with a relative humidity of $50-60 \%$ and a photoperiod of $12 / 12 \mathrm{~h}$ light/dark cycle) were individually housed in metabolic cages. Each group was fed during 16 weeks with an isocaloric diet supplemented with $10 \%$ of the oil under investigation: fish oil (F), olive oil (O) or coconut oil (C) (Segarra et al. 2008). Body weight (g) and food intake (g/day) were monitored throughout all the experimental period. At the end of the feeding period, rat brains were perfused with saline through the left cardiac ventricle under equithensin anesthesia (Segarra et al. 2017), quickly removed and cooled in dry ice. Samples of frontal cortex were dissected according to the stereotaxic atlas of Paxinos and Watson (1998). For each group, the left and right frontal lobes $(11.20 \mathrm{~mm}$ anterior to the interaural line) were collected, pooled, and separated in 2 aliquots, one for the determination of the protein content and enkephalinase activity and the other for the determination of fatty acids. All experimental procedures were in accordance with the European Communities Council Directive 86/609/EEC.
Isolation of soluble and membrane-bound enkephalinase. Tissue samples were homogenized in $400 \mu \mathrm{l}$ of $10 \mathrm{mM} \mathrm{HCl-Tris} \mathrm{buffer} \mathrm{(pH7.4)} \mathrm{and} \mathrm{ultra-}$ centrifuged at $100000 \times \mathrm{g}$ for $30 \mathrm{~min}$ at $4{ }^{\circ} \mathrm{C}$. The obtained supernatants were used to measure soluble enkephalinase activity and protein content in triplicate. To solubilize membrane proteins, the pellets were re-homogenized in HCl-Tris buffer ( $\mathrm{pH}$ 7.4) plus $1 \%$ Triton-X-100. After centrifugation $(100000 \times \mathrm{g}$, $30 \mathrm{~min}, 4^{\circ} \mathrm{C}$ ), the supernatants were shaken in an orbital rotor for $2 \mathrm{~h}$ at $4^{\circ} \mathrm{C}$ with the polymeric adsorbent Bio-Beads SM-2 $(100 \mathrm{mg} / \mathrm{ml})$ to remove the detergent from the sample. After bio-beads removal, these supernatants were used to measure membranebound enkephalinase activity and protein content in triplicate (Ramirez et al. 2011).

Enkephalinase activity. Soluble and membranebound enkephalinase activities in the frontal cortex were fluorometrically measured using L-Ala- $\beta$ naphthylamide (L-AlaNNap) as a substrate as previously described (Ramirez et al. 2011). The sensitivity of the method allows measurements in the pmol range. The coefficient of variation within the assays was $3.7 \%$. However, as the enzyme undergoes some autolytic process during the assay, it may vary slightly between different assays. To avoid this problem, all enzymatic measurements (for each group) were performed on the same day. Therefore, the different groups were analyzed and compared under similar conditions. Proteins were quantified in triplicate by the method of Bradford (1976) using BSA as a standard. Specific soluble and membrane-bound enkephalinase activities were expressed as nanomoles of L-AlaNNap hydrolyzed per minute per milligram of protein. Fluorogenic assays were linear with respect to the time of hydrolysis and the protein content.

Isolation of lipids and analysis of fatty acids. Lipids were extracted with chloroform/methanol $(2: 1, \mathrm{v} / \mathrm{v})$, according to Folch et al. (1957) and the chloroform phase was evaporated to dryness under vacuum (Speed-VAC, Savant Inc., Midland, MI, USA). The lipid residue was dissolved in toluene and spotted on thin-layer chromatography plates (SIL G-25, Macherey-Nagel, Duren, Germany). Plates were developed in $n$-heptane/diisopropyl ether/acetic acid (70:30:2, v/v/v.). After spraying the plate with an ethanolic solution of 2',7'-dichlorofluorescein, lipids were made visible under UV light. The bands were scraped and the fatty acids were transmethylated following Lepage and Roy (1986). The fatty acid methyl esters were analyzed with an HP5890 series II gas chromatograph fitted with a flame ionization detector. Samples were injected through the split 
injection port (split ratio, 30:1) onto a SP 2330 capillary column $(30 \mathrm{~m} \times 0.25 \mathrm{~mm}, 0.20 \mathrm{~mm}$ film thickness; Supelco Company, USA) (Ruiz-Sanz et al. 2001). Helium was used as carrier gas under a pressure of 0.5 bar and injector and detector temperatures were $250^{\circ} \mathrm{C}$. The oven temperature was programmed at $80^{\circ} \mathrm{C}$ for $1 \mathrm{~min}$, increased from 80 to $140^{\circ} \mathrm{C}$ at a rate of $50^{\circ} \mathrm{C} / \mathrm{min}$, then from 140 to $190^{\circ} \mathrm{C}$ at a rate of $5^{\circ} \mathrm{C} / \mathrm{min}$, and then held at $190^{\circ} \mathrm{C}$ for $5 \mathrm{~min}$. Finally, the temperature was increased from 190 to $210^{\circ} \mathrm{C}$ at a rate of $5^{\circ} \mathrm{C} / \mathrm{min}$ and held at $210^{\circ} \mathrm{C}$ for $15 \mathrm{~min}$. Individual fatty acids were identified by comparing relative retention times with commercial standards (Nu Chek, USA). Heptadecanoic acid was used as an internal standard.

Statistical analysis. To analyze differences between groups, one-way analysis of variance (ANOVA) was used. Post-hoc comparisons were made using the Student's t-test. The Pearson coefficient of fatty acid content and enkephalinase activity was computed using SPSS13.0 and STATA 90. The p-values below 0.05 were considered significant.

\section{Results}

At the end of the 16 weeks feeding period, body weight and food intake increased in the three groups studied. The final body weight did not differ between the three groups, but food intake was significantly higher $(\mathrm{p}<0.01)$ in the coconut-treated rats than in the other two groups, which did not differ between them (Figure 1).

Figure 2 represents the profiles of fatty acids in frontal cortex depending on the type of fat used in

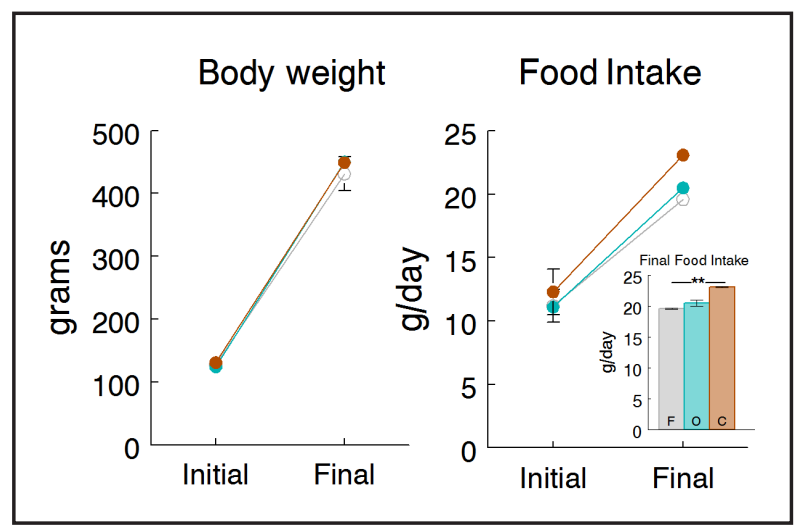

Figure 1. Initial (week 1) and final (week 16) values of body weight (g, mean \pm SEM) and food intake ( $g /$ day, mean \pm SEM) in animals fed fish oil- (F, grey), olive oil- (O, cyan) and coconut oil-enriched diet (C, brown). Asterisks indicate significant differences between groups. ${ }^{* *} \mathrm{p}<0.01$. the diet. The numerical values of this representation have previously been reported by Segarra et al. (2011). As earlier discussed (Segarra et al. 2011), the profiles clearly differed between the diets. The main differences were between the group fed a fish oil enriched diet and the two other groups which demonstrated minor differences between them. Compared with the olive oil group, there were few differences in the satu-

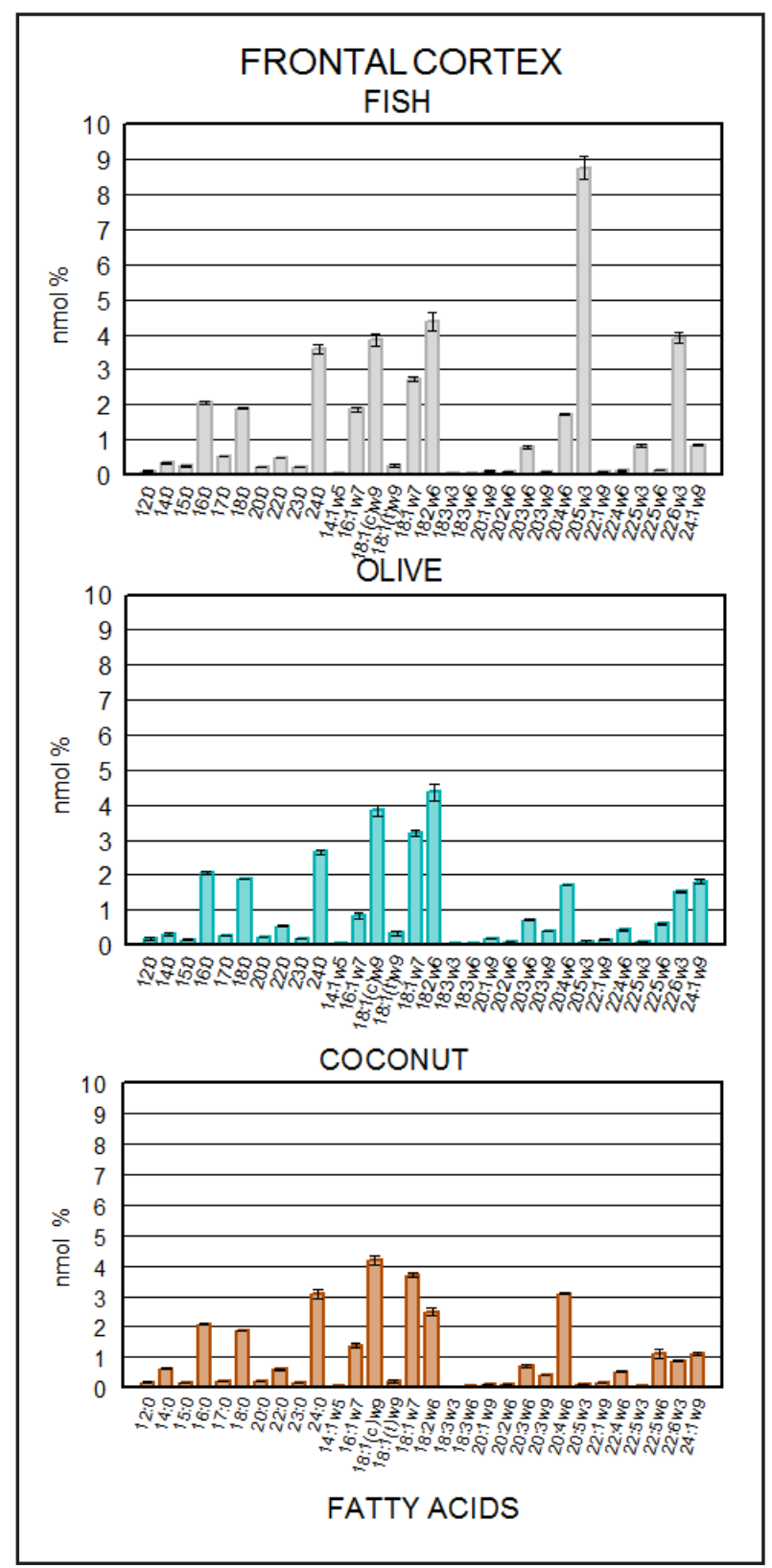

Figure 2. Profiles of individual fatty acids, expressed as nmol \% (mean \pm SEM), in frontal cortex of rats fed diets enriched with fish oil (grey bars), olive oil (cyan bars) or coconut oil (brown bars) (Segarra et al. 2011). 
rated fat deposition of rats fed fish oil except lignoceric acid (24:0) that increased. Regarding monounsaturated, palmitoleic acid (16:1 $1 \omega 7)$ also increased in the fish oil group. Polyunsaturated acids clearly increased in frontal cortex of rats fed fish oil in comparison with the ones fed olive oil. In comparison with coconut diet, linoleic (18:2 $\omega 6)$, eicosapentaenoic

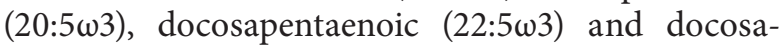
hexaepentaenoic (22:6 63$)$ acids increased largely in the fish oil group (Segarra et al. 2011).

The angiotensinase activities analyzed by Segarra et al. (2011) did not differ between groups. In contrast, the present data demonstrated significant differences between the diets for enkephalinase activities (Figure 3). Rats fed a diet enriched with

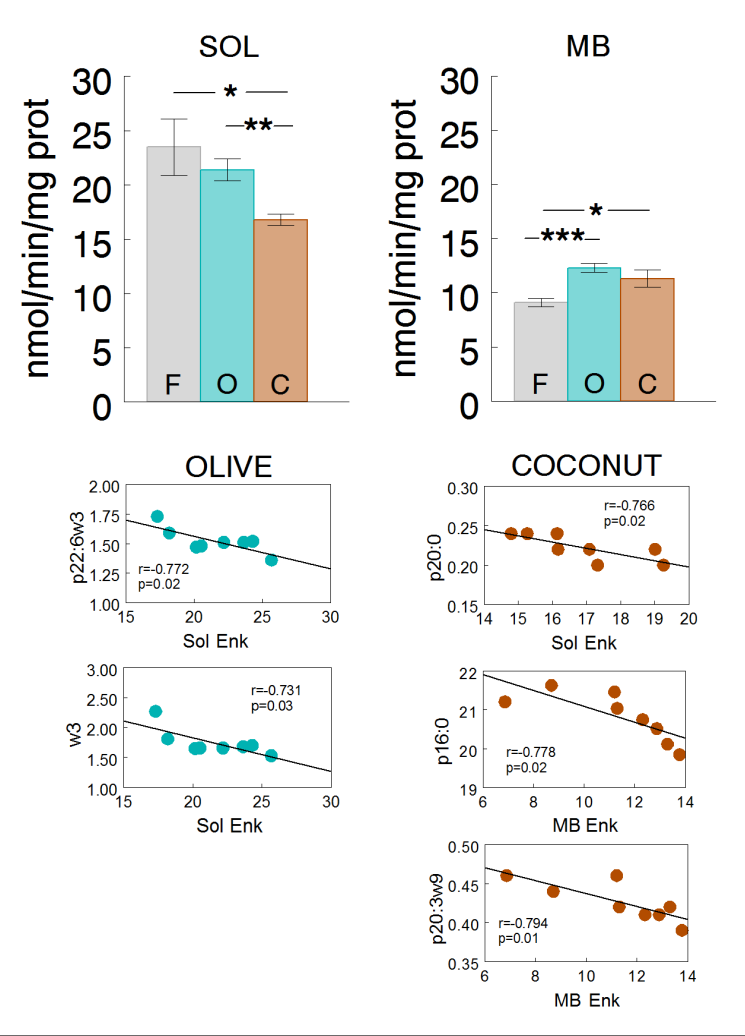

Figure 3. Soluble (SOL, Sol Enk) and membrane-bound (MB Enk) enkephalinase activities, expressed as nmol of Ala$\beta$-naphthylamide hydrolyzed per min per $\mathrm{mg}$ of proteins $($ mean $\pm S E M)$ in frontal cortex of rats fed diets enriched with fish oil (F, grey), olive oil (O, cyan) or coconut oil (C, brown). Asterisks indicate significant differences. ${ }^{\star} \mathrm{p}<0.05 ;{ }^{* *} \mathrm{p}<0.01$; ${ }^{* *} p<0.001$ (upper graphs). Lower graphs indicate the significant correlations ( $\mathrm{r} / \mathrm{p}$ values) observed between individual fatty acids, expressed as nmol \%, and soluble or membranebound enkephalinase activities in animals fed diets enriched with olive (cyan) or coconut (brown) oils. No correlations were observed in the group fed with fish oil. coconut oil had lower soluble enkephalinase levels of activity than the group fed olive oil $(\mathrm{p}<0.01)$ or fish oil $(\mathrm{p}<0.05)$. Moreover, rats fed a diet enriched with fish oil had lower membrane-bound enkephalinase activity than the group fed with olive $(\mathrm{p}<0.001)$ or coconut oil $(p<0.05)$. While no significant correlations between fatty acids and enkephalinase activities were observed in the group fed a diet enriched with fish oil, significant negative correlations were demonstrated in the groups fed with olive and coconut oils (Figure 3). The higher level of soluble enkephalinase activity, the lower level of docosahexaenoic acid $(\mathrm{p} 22: 6 \omega 3)(\mathrm{r}=-0.772, \mathrm{p}=0.02)$ and mean levels of $\omega 3$ $(\mathrm{r}=-0.731, \mathrm{p}=0.03)$ in the olive oil group and arachidic acid (p20:0) $(\mathrm{r}=-0.766, \mathrm{p}=0.02)$ in the coconut group. In addition, the higher levels of membrane-bound enkephalinase activity, the lower levels of palmitic acid (p16:0) $(\mathrm{r}=-0.778, \mathrm{p}=0.02)$ and mead acid (p20:3 $\omega 9)(\mathrm{r}=-0.794, \mathrm{p}=0.01)$ in the coconut group.

\section{Discussion}

Brain polyunsaturated $\omega 3$ fatty acids and particularly docosahexaenoic acid (DHA, p22:6 $\omega 3$ ) are important to improve brain development and cognitive functions. The deficit of DHA has been related to alteration of learning and memory, dementia and neurodegenerative disorders and its administration improves memory acquisition and ameliorates some symptoms in rat models of Alzheimer's disease (Hashimoto et al. 2017). In contrast, saturated fatty acids such as arachidic (C20:0) (Iuliano et al. 2013; Nasaruddin et al. 2018) and palmitic acids (C16:0) (Moon et al. 2014; Schommer et al. 2018) have been respectively related to Alzheimer's disease and anxiety-like behavior, together with an increase of $\alpha$-synuclein. In addition, mead acid (20:3 $\omega 9)$ levels were higher in plasma of patients with Alzheimer's disease than in healthy controls (Iuliano et al. 2013).

Therefore, our results demonstrate that in animals fed an olive oil enriched diet enkephalinase activity correlates with $\omega 3$ fatty acids reported as beneficial for brain function. In contrast, in the coconut group enkephalinase activity correlates with fatty acids reported as deleterious for brain function.

Moreover, since enkephalins were related with food intake (Mendez et al. 2015), the higher food intake observed in the coconut group might be related to the differences between diets observed for enkephalinase activities.

These results demonstrated that the profile of fatty acids and the levels of enkephalinase activity are modified depending on the type of fat used 
in the diet. Further, there are significant correlations between these two factors. Chang et al. (2010) comparing control rats with high-fat consumer rats, have demonstrated a higher expression of enkephalin mRNA in the paraventricular nucleus, nucleus accumbens and central nucleus of the amygdala in the high fat diet group. This increased expression was related to the rise in circulating levels of triglycerides (Chang et al. 2007). To our knowledge, the present data report as the first a relation between the type of fat used in the diet and enkephalinase activity in frontal cortex.

Our results demonstrate that when an enriched diet in olive oil was used, a negative correlation between $\omega 3$ and soluble enkephalinase activity was observed: the higher the level of enkephalinase activity, the lower the level of $\omega 3$ acids. Therefore, considering the relationship high enkephalinase activity/low enkephalin level and vice versa, the results suggest low enkephalin together with low $\omega 3$ or high enkephalin together with high $\omega 3$. This may be interpreted as a direct or indirect complementary relationship between enkephalin and $\omega 3$ under a diet enriched with olive oil.

Furthermore, our results also demonstrate that when the diet was enriched with coconut oil a negative relationship between the saturated fatty acids arachidic, palmitic and mead acids versus soluble and membrane-bound enkephalinase activity was observed: the higher the level of enkephalinase activity, the lower the level of these fatty acids. Therefore, considering the relation high enkephalinase activity/low level of enkephalin and vice versa, our results suggest again low enkephalin together with low saturated and mead acids or vice versa. This may be interpreted as a direct or indirect compensatory relationship between enkephalin and these deleterious fatty acids under a diet enriched with coconut oil.

In addition, enkephalins in the frontal cortex have been related to some of the functions linked to this area, for instance the modulation of pain or cognitive processes such as anxiety or depression (Hardy and Haigler 1985; Henry et al. 2017). As enzymes that regulate the activity of the enkephalins are modified depending on the type of fat in the diet, this observation may be important for designing therapeutic strategies that not only consider inhibitors or activators of enkephalinase activity but also take into account physiological factors that modify these activities such as for example circadian rhythm (Dominguez-Vias et al. 2018), gender (de Gandarias et al. 1989), phase of the ovarian cycle (de Gandarias et al. 1988) or, as in the present study, the type of diet.

\section{Acknowledgements}

This work was supported by the research group "Neuroendocrinology and Nutrition" BIO-221.

\section{References}

Banegas I, Prieto I, Segarra AB, Vives F, de Gasparo M, Duran R, de Dios Luna J, Ramirez-Sanchez M. Bilateral distribution of enkephalinase activity in the medial prefrontal cortex differs between WKY and SHR rats unilaterally lesioned with 6-hydroxydopamine. Prog Neuropsychopharmacol Biol Psychiatry 75, 213-218, 2017.

Bodnar RJ. Endogenous Opiates and Behavior: 2016. Peptides 101, 167-212. 2018.

Bradford MM. A rapid and sensitive method for the quantitation of microgram quantities of protein utilizing the principle of protein-dye binding. Anal Biochem 72, 248-254, 1976.

Chang GQ, Karatayev O, Ahsan R, Gaysinskaya V, Marwil Z, Leibowitz SF. Dietary fat stimulates endogenous enkephalin and dynorphin in the paraventricular nucleus: role of circulating triglycerides. Am J Physiol Endocrinol Metab 292, E561-E570, 2007.

Chang GQ, Karatayev O, Barson JR, Chang SY, Leibowitz SF. Increased encephalin in brain of rats prone to overconsuming a fat-rich diet. Physiol Behav 101, 360-369, 2010.

Corder G, Castro DC, Bruchas MR, Scherrer G. Endogenous and exogenous opioids in pain. Annu Rev Neurosci 41, 453-473, 2018.

Danziger RS. Aminopeptidase N in arterial hypertension. Heart Fail Rev 13, 293-298, 2007.

de Gandarias JM, Casis L, Irazusta J, Echevarria E, Ramirez M. Changes of aminopeptidase activity levels in serum and brain during the estrous cycle of the rat. Horm Metab Res 20, 776, 1988.

de Gandarias JM, Ramirez M, Zulaica J, Casis L. Aminopeptidase (arylamidase) activity in discrete areas of the rat brain: sex differences. Horm Metab Res 21, 285-286, 1989.

Dominguez-Vias G, Aretxaga-Maza G, Prieto I, Segarra AB, Luna JD, de Gasparo M, Ramirez-Sanchez M. Lightdark influence of enkephalinase activity in hypothalamus and pituitary. Neuro Endocrinol Lett 39, 277-280, 2018. 
Folch J, Less M, Sloane-Stanley GH. A simple method for the isolation and purification of total lipids from animal tissues. J Biol Chem 226, 497-509, 1957.

Gibson AM, Biggins JA, Lauffart B, Mantle D, McDermott JR. Human brain leucyl aminopeptidase: isolation, characterization and specificity against some neuropeptides. Neuropeptides 19, 163-168, 1991.

Hardy SG, Haigler HJ. Prefrontal influences upon the midbrain: a possible route for pain modulation. Brain Res 339, 285-293, 1985.

Hashimoto M, Hossain S, Al Mamun A, Matsuzaki K, Arai H. Docosahexaenoic acid: one molecule diverse functions. Crit Rev Biotechnol 37, 579-597, 2017.

Henry MS, Gendron L, Tremblay ME, Drolet G. Enkephalins: Endogenous analgesics with an emerging role in stress resilience. Neural Plast 2017, 1546125, 2017.

Hernandez J, Prieto I, Segarra AB, de Gasparo M, Wangensteen R, Villarejo AB, Banegas I, Vives F, Cobo J, RamirezSanchez M. Interaction of neuropeptidase activities in cortico-limbic regions after acute restraint stress. Behav Brain Res 287, 42-48, 2015.

Hersh LB. Characterization of membrane-bound aminopeptidases from rat brain: identification of the enkephalindegrading aminopeptidase. J Neurochem 44, 1427-1435, 1985.

Hersh LB, Aboukhair N, Watson S. Immunohistochemical localization of aminopeptidase M in rat brain and periphery: relationship of enzyme localization and enkephalin metabolism. Peptides 8, 523-532, 1987.

Iuliano L, Pacelli A, Ciacciarelli M, Zerbinati C, Fagioli S, Piras F, Orfei MD, Bossu P, Pazzelli F, Serviddio G, Caltagirone C, Spalletta G. Plasma fatty acid lipidomics in amnestic mild cognitive impairment and Alzheimer's disease. J Alzheimers Dis 36, 545-553, 2013.

Lepage G, Roy CG. Direct transesterifi cation of all classes of lipids in a one step reaction. J Lipid Res 27, 114-120, 1986.

Matsumoto H, Nagasaka T, Hattori A, Rogi T, Tsuruoka N, Mizutani S, Tsujimoto M. Expression of placental leucine aminopeptidase/oxytocinase in neuronal cells and its action on neuronal peptides. Eur J Biochem 268, 3259-3266, 2001.

Mendez IA, Ostlund SB, Maidment NT, Murphy NP. Involvement of endogenous enkephalins and $\beta$-endorphin in feeding and diet-induced obesity. Neuropsychopharmacology 40, 2103-2112, 2015.

Moon ML, Joesting JJ, Lawson MA, Chiu GS, Blevins NA, Kwakwa KA, Freund GG. The saturated fatty acid, palmitic acid, induces anxiety-like behavior in mice. Metabolism 63, 1131-1140, 2014.

Narita M, Kaneko C, Miyoshi K, Nagumo Y, Kuzumaki N, Nakajima M, Nanjo K, Matsuzawa K, Yamazaki M, Suzuki T. Chronic pain induces anxiety with concomitant changes in opioidergic function in the amygdala. Neuropsychopharmacology 31, 739-750, 2006.

Nasaruddin ML, Pan X, McGuinness B, Passmore P, Kehoe PG, Holscher C, Graham SF, Green BD. Evidence that parietal lobe fatty acids may be more profoundly affected in moderate Alzheimer's disease (AD) pathology than in severe AD pathology. Metabolites 8, pii: E69, 2018.

Paxinos G, Watson C. The Rat brain in stereotaxic coordinates. 4th ed. London: Academic Press, 1998.

Ramirez M, Prieto I, Banegas I, Segarra AB, Alba F. Neuropeptidases. Methods Mol Biol 789, 287-294, 2011.

Ruiz-Sanz JI, Navarro R, Martinez R, Martin C, Lacort M, Matorras R, Ruiz-Larrea MB. 17beta-estradiol affects in vivo the low density lipoprotein composition, particle size, and oxidizability. Free Radic Biol Med 31, 391-397, 2001.

Schommer J, Marwarha G, Nagamoto-Combs K, Ghribi O. Palmitic acid-enriched diet increases a-sSynuclein and tyrosine hydroxylase expression levels in the mouse brain. Front Neurosci 12, 552, 2018.

Segarra AB, Ramirez M, Banegas I, Alba F, Vives F, de Gasparo M, Ortega E, Ruiz E, Prieto I. Dietary fat influences testosterone, cholesterol, aminopeptidase A, and blood pressure in male rats. Horm Metab Res 40, 289-291, 2008.

Segarra AB, Ruiz-Sanz JI, Ruiz-Larrea MB, Ramirez-Sanchez M, de Gasparo M, Banegas I, Martinez-Canamero M, Vives F, Prieto I. The profile of fatty acids in frontal cortex of rats depends on the type of fat used in the diet and correlates with neuropeptidase activities. Horm Metab Res 43, 86-91, 2011.

Thompson MW, Hersh LB. The puromycinsensitive aminopeptidase; in Hooper NM, Lendeckel U (eds): Aminopeptidases in Biology and Disease. Kluwer Academic/Plenum, New York, 2004, pp 1-15. 